\title{
HYPOMAGNESAEMIA AND HYPOCALCEMIA THE MAJOR MISSED OUT CLINICAL CONDITION IN MANAGEMENT OF DIABETES
}

\author{
Divya $S^{l}$, Fahima Sheerin $S M H^{l}$, Chindhiha $S^{l}$, Suganthi $M^{2}$, Sherafin Vincyl, \\ Chandrasekar $M^{1}$, Selvakumar $K^{3}$
}

\begin{abstract}
${ }^{1}$ Department of Medical Laboratory Technology, Loyola College, Nungambakkam Chennai, India
${ }^{2}$ Post Doctoral Fellow, Centre for Biotechnology, Anna University, Guindy Chennai, India ${ }^{3}$ Senior Research Officer, Indian Diabetes Research Foundation, The Tamilnadu Dr. MGR Medical University, Chennai and Department of Clinical Biochemistry, Billroth Hospitals, Shenoy Nagar, Chennai, India.
\end{abstract}

\section{Abstract}

Background: Magnesium \& Calcium are essential factors for insulin to get released from the pancreatic cell. To evaluate the relation of hypomagnesemia and hypocalcemia in the glycaemic control and to analyze the importance of both in the insulin secretion mechanism. Method: A total of 239 individuals were selected for this study. HbA1c level, serum electrolytes, magnesium, and Calcium were assessed for all the individuals. Results: Out of 239 individuals, 79 were uncontrolled diabetic by calculating $\mathrm{HbA1C}$ as a gold standard; the ratio was higher in males. Hypocalcemia is present in both individuals; females $(31 \%)$ are much prone to sodium $(\mathrm{Na})$ and potassium $(\mathrm{K})$ than males (20\%). Females are highly affected by electrolyte imbalance, but in hypomagnesemia diabetic individuals, the males are high in electrolyte imbalance. Conclusion: Since $\mathrm{Mg}$ and Ca plays a vital role in insulin synthesis, secretion, repair, and alteration, along with the hypoglycaemic agents, the supplementation of magnesium or Calcium could be suggested via dietary or drug supplements. In addition to this, regular monitoring of electrolytes is essential to maintain fluid balance.

KEYWORDS: Magnesium; Calcium; Insulin secretion; Uncontrolled diabetes; Electrolytes

\section{INTRODUCTION}

$\mathrm{D}$ iabetes is one of the known, most common non-communicable diseases globally. Population growth, urbanization, aging, physical inactivity, and increasing prevalence of obesity are several reasons the number is increasing. Diabetes mellitus (DM) is a group of metabolic disorders with high blood sugar, characterized as hyperglycemia, including frequent urination, increased thirst, and increased hunger [1,2]. DM is a chronic metabolic disorder resulting from defective insulin secretion or insulin resistance [3]. Insulin resistance (IR) is related to an impaired biological reaction to insulin stimulation of critical target tissues and impacts glucose utilization, resulting in a compensatory rise in beta-cell insulin production and hyperinsulinemia. It leads to metabolic syndrome and type 2 diabetes mellitus $[4,5]$.

Glycosylated hemoglobin (HbA1c) is the critical target of glycaemic control. It is the gold standard in analyzing one's status of the average blood glucose during the past three months. The desirable rate for $\mathrm{HbA} 1 \mathrm{c}$ values below $7.0 \%$ and is also raised in diabetes individuals with hypomagnesemia [6]. Electrolyte imbalance is frequently existing in individuals with type 2 diabetes mellitus (T2DM) [7]. These play an essential role in the human body, for instance, controlling fluid levels, acid-base balance $(\mathrm{pH})$, etc. Electrolyte imbalance causing by dehydration, fever, kidney failure, and vomiting has been implied as one of the contributing aspects in the complications observed in diabetes [8].

Correspondence: Dr. K. Selvakumar, Department of Clinical Biochemistry, Billroth Hospitals,

Shenoy Nagar, Chennai, India. E-mail: bennysgod@gmail.com

eISSN: 2395-0471

pISSN: 2521-0394

DOI: $10.31878 /$ ijcbr.2021.72.04
(C) Authors; 2021. (CC BY-NC-SA 4.0)

This is an Open Access article which permits unrestricted

non-commercial use, provided the original work is properly cited. 
Magnesium (Mg) is the fourth most abundant cation, and after potassium, it is the second most abundant intracellular cation in the human body. It has numerous systems like regulating several significant functions such as glycaemic control, muscle contraction, myocardial contraction, neuromuscular conduction, and blood pressure $[9,10]$. According to the enzymatic databases list, $\mathrm{Mg} 2+$ acts as a cofactor for more than 600 enzymes and a further 200 in which Mg2+ may act as an activator [11]. Normal serum magnesium levels are in a range of $0.75-0.95 \mathrm{mmol} / 1(1.7-2.3 \mathrm{mg} /$ dl). Clinically, hypomagnesemia is characterized as a serum $\mathrm{Mg}$ concentration $\leq 1.6 \mathrm{mg} / \mathrm{dl}$ [12]. The prevalence of hypomagnesemia in DM is 65\%. The DM with hypomagnesemia has been found to confer increased risk in those individuals [13].

Magnesium act as an essential cofactor for several enzymes that take part in carbohydrate metabolism. Magnesium functions as an insulin sensitizer by regulating tyrosine kinase activity on insulin receptors and autophosphorylation of these receptors [14.15].

$$
\begin{aligned}
& \text { Glucose }+ \text { ATP } \stackrel{\text { HK,Mg2+ }}{\longrightarrow} \text { Glucose-6-phosphate }+ \text { ADP } \\
& \text { Glucose-6-Phosphate }+ \text { NAD }^{+} \stackrel{\text { G6P-DH }}{\longrightarrow} \text { Gluconate-6-P }+ \text { NADH }+\mathrm{H}^{+}
\end{aligned}
$$

Calcium $(\mathrm{Ca})$ plays a key role in glucose uptake once insulin binds muscle cells and in muscle contractions. Also, Calcium influences the affinity of insulin receptors and sensitivity to insulin. The insensitivity of liver, muscle, and adipose tissue to insulin muscle is one of the major sites liable for insulin resistance [16]. Hypocalcaemia is analysed by a total serum calcium concentration $<8.8 \mathrm{mg} /$ $\mathrm{dL}(<2.20 \mathrm{mmol} / \mathrm{L})$. Acute hypocalcemia can result in serious symptoms requiring hospitalization, while the individuals who progressively develop hypocalcemia are prone to be asymptomatic [17]. A trial of $\mathrm{Mg} 2+$ administration is commonly enquired in the presence of hypocalcemia. In general, Mg2+, an essential secondary messenger initiating or regulating several cellular functions in various cells, is considered the main antagonist of $\mathrm{Ca} 2+[18]$.

Insulin secretion is a Calcium dependant biological process, and a rise in Calcium is needed for both the first and second phases of insulin secretion [19]. The intracellular calcium changes in primary insulin target tissues may contribute to the peripheral insulin resistance via impaired insulin signal transduction to reduce GLUT 4 activity [20]. Ca2+ dependent enzymes, Cytosolic $\mathrm{Ca} 2+$, and $\mathrm{Ca} 2+$ channels are relatively involved in glucose uptake by muscle cells [21].

\section{Insulin secretion mechanism}

Pancreatic beta cells can synthesize, store and release insulin in response to various metabolic reactions. The process of insulin secretion from the $\beta$ cells is controlled by the KATP channel closure, L-type calcium channels, and magnesium $(\mathrm{Mg} 2+)$. The secretion of insulin is triggered by invading glucose molecules to the $\beta$ cells via glucose transporter type 2 (GLUT 2) from the bloodstream, where the glucose is converted to glucose-6-phosphate (G6P) by the enzyme called glucokinase. G6P is further processed in glycolysis which produces ATP and causes an increase in ATP/ADP ratio; $\mathrm{Mg} 2+$ directly influences the rate of glucokinase enzyme activity by acting as a cofactor adenine nucleotides (MgATP).

Now, more ATP is present inside the cells, which binds with the receptor of KATP channels. KATP channel consists of four central inwardly rectifying receptors (Kir6.2) and the surrounding four receptors called sulphonylurea (SUR1) subunit. The binding of MgATP controls the opening of this channel to SUR1; closing of the channel depends on the binding of ATP to Kir6.2. This binding leads to the closing of KATP channels and thus stops the potassium from proceeding out of the cell. On the other hand, a large amount of potassium inside the cell induces depolarization action, which helps open L-type calcium channels, which release Calcium, and the receptor binds with and forms a complex secretory granule of insulin. As of result of this signaling mechanism, the insulin got released from the pancreatic beta cells. The Calcium binds and releases insulin action, which $\mathrm{Mg} 2+$ negatively controls.

\section{Material And Methodology}

\section{Study design: An analytical study}

Ethics approval: the study was approved by the institutional ethics committee.

Locus of study: Billroth Hospitals, Shenoy Nagar, Chennai, Tamil Nadu

Sample size: The study was conducted on 239 patients' irrespective of age, who randomly came to the laboratory for diagnosis of $\mathrm{HbA} 1 \mathrm{C}$, magnesium, and Calcium

Inclusion criteria: Both men and women, irrespective of their age, are included in the study, individuals have $\mathrm{HbA} 1 \mathrm{c}>7 \%$ for more than three years without control. The person with low levels of Magnesium and Calcium.

Exclusion criteria: Individuals with type 1 diabetes, diabetic nephropathy were excluded

Sample Collection: Based on the requisition given by the consultant, the blood samples were collected from the individuals by the Phlebotomist in Billroth Hospital. Blood samples were collected in the Becton Dickinson (BD) Vacutainer ${ }^{\circledR}$ with K2 Ethylene diamine tetraacetic acid (EDTA) and Plain Tube for serum analysis.

Sample Centrifugation: Vacutainers with EDTA 
were put into the mixer until the process of Glycated Haemoglobin. Blood collected in plain Vacutainer ${ }^{\circledR}$ could clot and centrifuge at 5000 rpm for 20 minutes. The obtained serum was used to analyze the serum magnesium, Calcium, and electrolytes (sodium and potassium). In addition, a sample separated with the fluoride tube was used for obtaining plasma glucose.

Methodology: All the process was automated and done in the biochemistry laboratory, Billroth hospitals. Estimation of Magnesium, Calcium, and Glucose was done in Beckman Coulter AU480 by the photometric method using Xylidyl blue, Arsenazo III, and Hexokinase method, respectively. Estimating of $\mathrm{HbA} 1 \mathrm{c}$ in Biorad D10 using ion-exchange high-performance liquid chromatography (HPLC) and the estimation of electrolytes like sodium and potassium in ST 200CC - Electrolytes analyzer by using ion sensing electrode method.

\section{Results}

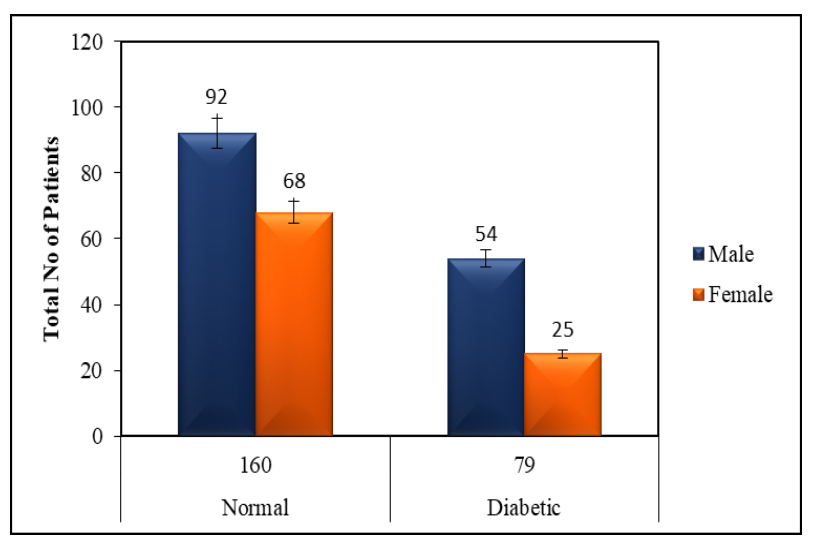

Each bar represents the total no. of normal Vs diabetic individuals and the categorization of male and female. Statistically $5 \%$ of the total occurrence was considered as a Standard Error (SE) for the statistical significance

Fig 1. Assessment of Diabetes using HBA1c(Glycosylated Haemoglobin) among the study group with gender difference

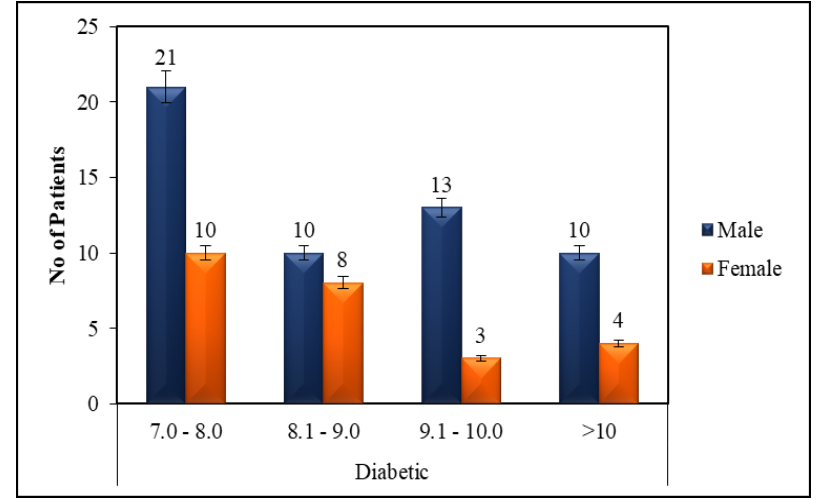

Each bar represents the total no. of diabetic individuals according to their severity of $\mathrm{HbA} 1 \mathrm{c}$ levels and the categorization of male and female. Statistically 5\% of the total occurrence was considered as a Standard Error (SE) for the statistical significance

Fig 2. Evaluation of management of diabetes using $\mathrm{HbA} 1 \mathrm{c}$ as a gold standard and the gender differences

Among the 239 individuals, the diabetic individuals were separated based on their measurement of HbA1c (Glycosylated Haemoglobin) level, the individuals with $>6.5 \%$ of $\mathrm{HbA} 1 \mathrm{c}$ were considered as diabetic. Out of 239 individuals, 160 were normal, and 79 were diabetic. Among 79 diabetic individuals, 54 were male, and 25 were female, these 79 patients were selected for the study and related parameters were analyzed.

The diabetic individuals were selected based on Fig. 1. The severity of the diabetes was studied for those male and female individuals based on their HbA1c levels $(7.1-8.0,8.1-9.0,9.1-10.0$, $<10.0 \%$ ). Our study categories of HbA1c levels as $7.1-8.0 \%$ Mild, $8.1-9.0 \%$ Moderate, 9.1$10.0 \%$ Severe, $>10 \%$ : High risk for multiorgan complication. Our study shows that a more significant number of individuals were falls under the category of $7.1-8.0 \%$.

The total number of diabetic individuals was separated according to the severity levels of $\mathrm{HbA} 1 \mathrm{c}$ and the age intervals. The age intervals

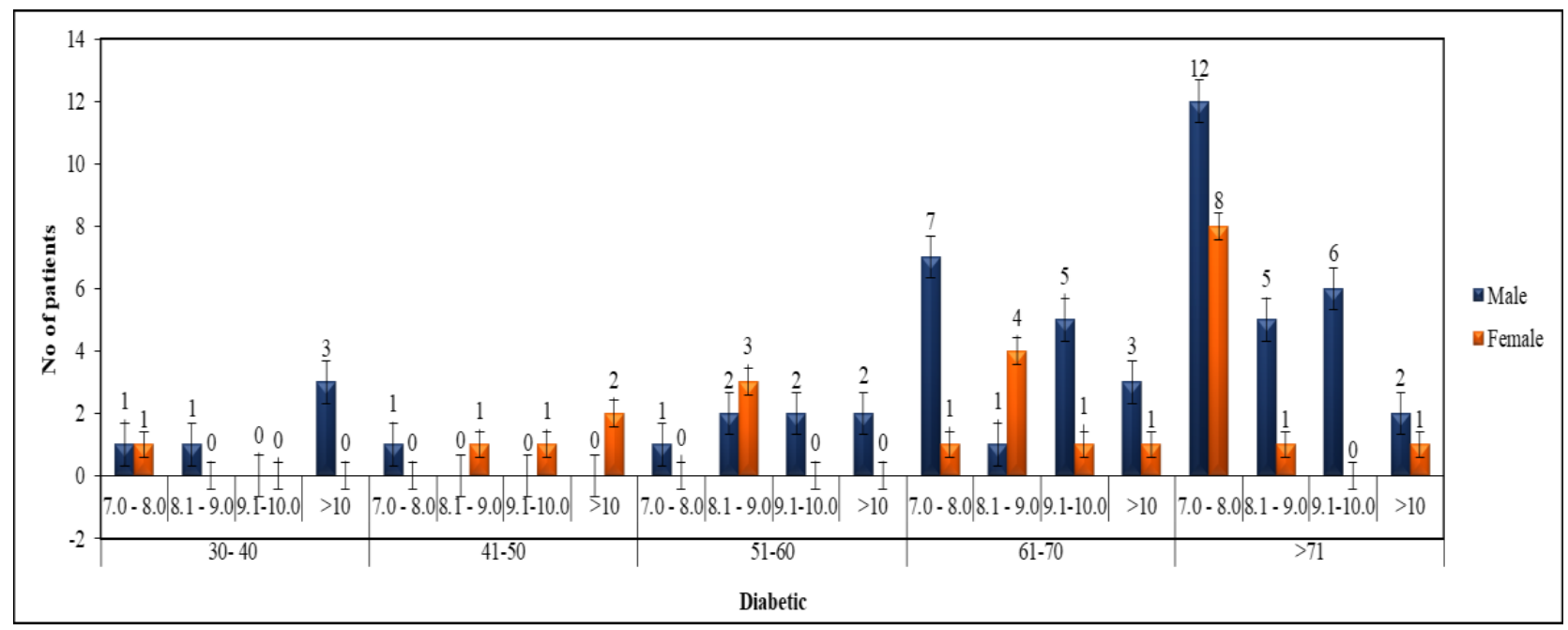

Each bar represents the total no. of diabetic individuals related to their HbAlc level and the categorization of male and female in different age intervals. Statistically $5 \%$ of the total occurrence was considered as a Standard Error (SE) for the statistical significance

Fig 3. Evaluation of management of diabetes using HbA1c based on age and gender differences

Int. J. Clin. Biomed. Res. 2021;7(2):16-22 
of the individuals divided for this study were 30-40, 41-50, 51-60, 61-70, and more than 71. In addition, the severity of the HbA1c level (as fig. 2.) was checked for the above-mentioned individuals. By this evaluation, the most affected individuals were found to be at the age was more than 71 who falls in the category of HbA1c level (7.1-8.0\%).

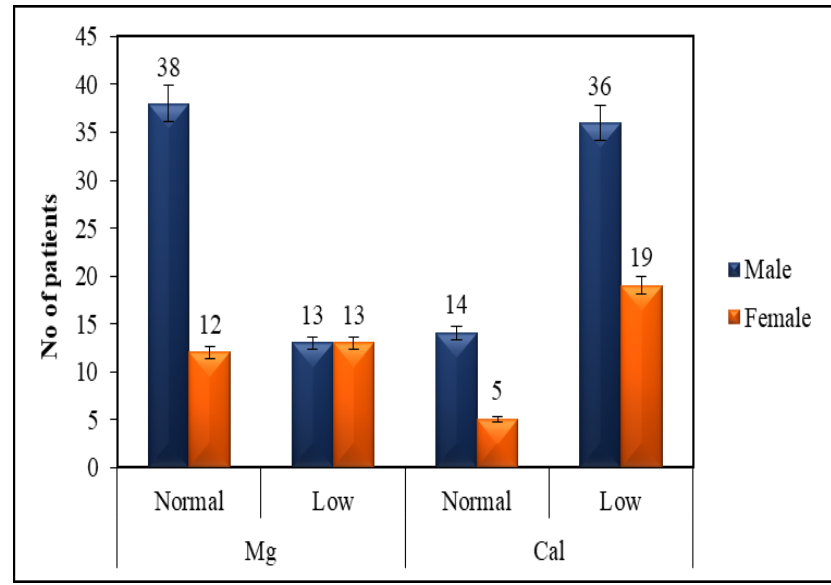

Each bar represents the no. of diabetes individuals corresponding to their magnesium level $v$ s calcium levels and the categorization of male and female. Statistically 5\% of the total occurrence was considered as a Standard Error (SE) for the statistical significance.

Fig 4. Estimation of serum magnesium and calcium levels in diabetes individuals with gender difference

Fig. 4. represents the estimation of serum magnesium and calcium levels in diabetic individuals. This study reveals hypomagnesemia and hypocalcemia in diabetic individuals. A more significant number of diabetic individuals were low in calcium levels while comparing with magnesium levels.

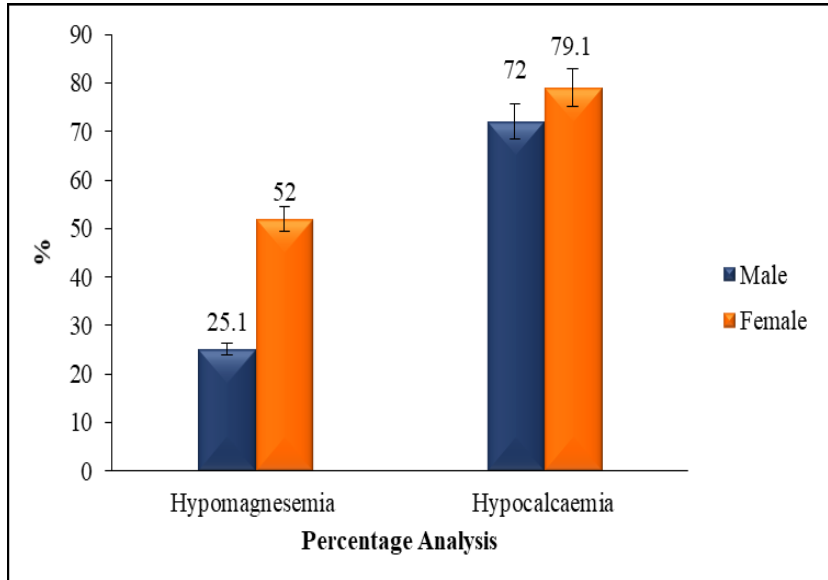

Each bar represents the percentage analysis of diabetic individuals with hypomagnesemia vs hypocalcaemia and the categorization of male and female. Statistically 5\% of the total occurrence was considered as a Standard Error (SE) for the statistical significance.

Fig 5. Percentage analysis of hypomagnesemia and hypocalcemia cases in fig. 4. with gender difference

The percentage analysis for the diabetic individuals with hypomagnesemia and hypocalcemia obtained from fig. 4. were calculated. By this analysis, females were much prone to both hypomagnesemia and hypocalcemia compared to males with diabetes was identified. By comparing hypomagnesemia and hypocalcemia cases, diabetes with hypocalcemia individuals was higher in number.

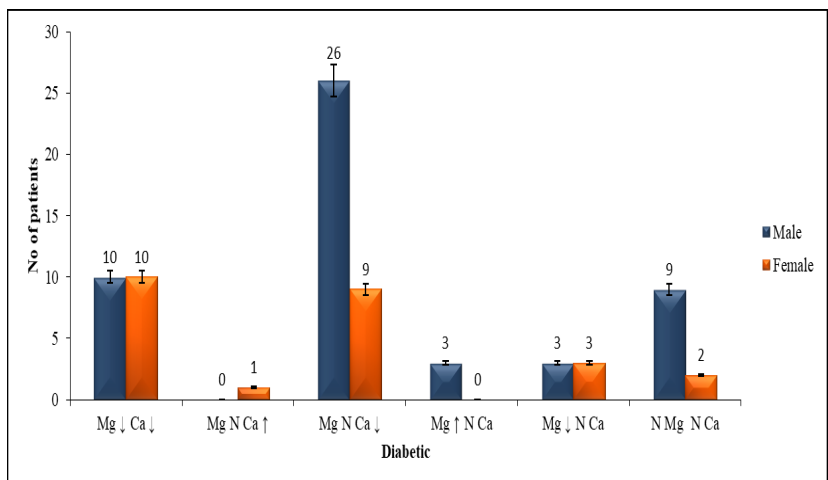

Each bar represents the no. of diabetic individuals to their correlation of $\mathrm{Mg}$ and Ca levels and the categorization of male and female. Statistically 5\% of the total occurrence was considered as a Standard Error (SE) for the statistical significance.

Fig 6. Correlation of magnesium and calcium levels in a differential proposition of diabetic individuals with gender difference

The correlation of magnesium and Calcium were checked for all the diabetic individuals. The differential proposition like $\mathrm{Mg} \downarrow \& \mathrm{Ca} \downarrow, \mathrm{Mg}$ normal $\& \mathrm{Ca} \downarrow, \mathrm{Mg}$ normal \& $\mathrm{Ca} \uparrow, \mathrm{Mg} \uparrow \& \mathrm{Ca}$ normal, $\mathrm{Mg} \downarrow$ $\& \mathrm{Ca}$ normal, and Mg normal \& Ca normal were checked. There is no significant change in all other groups except Mg normal \& Ca $\downarrow$ correlated individuals who were more. This study shows that most diabetic individuals are $\mathrm{Mg}$ normal \& Ca $\downarrow$; even more, the study significantly identifies that males $(35 \%)$ are high in percentage than females $(29 \%)$. The percentage of both levels of magnesium and Calcium are low in female (31\%) than male $(20 \%)$.

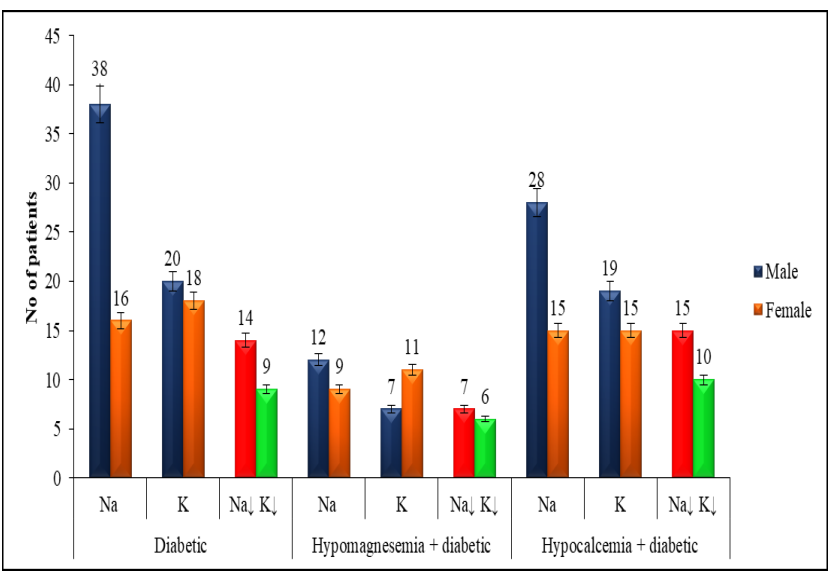

Each bar represents the electrolytes levels and the correlation of electrolytes (sodium and potassium) in diabetic individuals $v s$ hypomagnesemia and diabetic individual's $v$ s hypocalcaemia and diabetic individuals with the categorization of male and female. Statistically $5 \%$ of the total occurrence was considered as a Standard Error (SE) for the statistical significance.

Fig 7. Consideration of serum electrolytes level (sodium and potassium) in diabetic individuals with gender difference

The electrolyte level in Diabetic individuals: Serum sodium and potassium levels were analyzed for all the diabetic individuals. Low sodium, Low potassium Vs. both levels ( $\mathrm{Na} \&$ 
K) are low were assessed; the study shows that females are prone to low levels of electrolytes than males.

Electrolyte levels in hypomagnesemia diabetic individuals : Low serum sodium levels were found in males, whereas low potassium was found in females. While comparing with hypomagnesemia diabetic individuals, both the electrolytes were found low in males.

Electrolyte levels in hypocalcemia diabetic individuals: The individuals who have low sodium, low potassium Vs. both electrolytes were assessed. The study significantly declares that all the levels (electrolytes) separately and in combination are low in hypocalcemia diabetic females.

\section{Discussion}

The DM is a chronic metabolic illness that is from defective insulin secretion or insulin resistance. Magnesium deficiency was found to be significantly associated with lowered insulindependent glucose uptake and increased incidence of diabetes mellitus [23]. Diabetic individuals with hypomagnesemia are noted to have enhanced resistance to insulin and poor control of their blood glucose levels. Diabetes individuals can also develop hypocalcemia since Calcium is essential for insulin-mediated intracellular processes in insulin-responsive tissues like adipose tissue, with a very narrow range of intracellular Calcium needed for optimal insulin-mediated functions. Calcium and magnesium play a vital role in the course of insulin secretion.

The purpose of our study is to analyze the significant role of hypo magnesium and hypo calcium in the insulin signaling pathway of uncontrolled type II diabetic individuals without any age or gender difference. Hypomagnesemia is often present in patients with diabetes mellitus, and it appears that its prevalence increases with the period of diabetes mellitus [24]. Similarly, our study shows that most of the diabetic individual's HbA1c levels are between 7.1 to 8.0, elderly people are most affected, and hypomagnesemia is present in some individuals.

Magnesium $(\mathrm{Mg} 2+)$ is an essential mineral and plays a vital role in insulin actions and the regulation of glucose homeostasis. It plays a vital role in the insulin secretion pathway; Mg2+ acts as a cofactor for adenine nucleotides (MgATP) and directly influences the amount of glucokinase enzyme activity [22]. Hypomagnesemia occurs at 13.5 to $47.7 \%$ among individuals with type 2 diabetes [25]. For uncontrolled diabetic individuals', the tyrosine kinase activity is inhibited by the low level of magnesium and thus causes problems in insulin secretion. In the present study, we examined the magnesium levels in type 2 diabetic individuals, which showed a significant change in a low level of magnesium was found more in females (52\%).

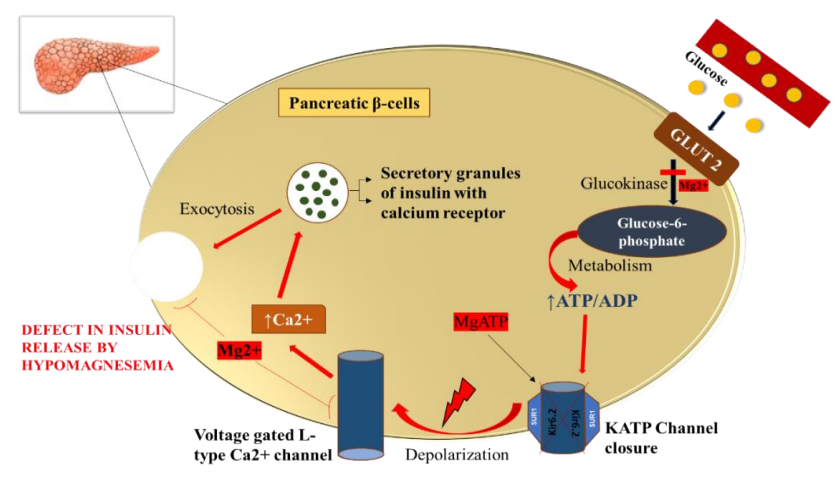

Fig 8. Defective insulin secretion by hypomagnesemia (modified from Kostov, 2019)

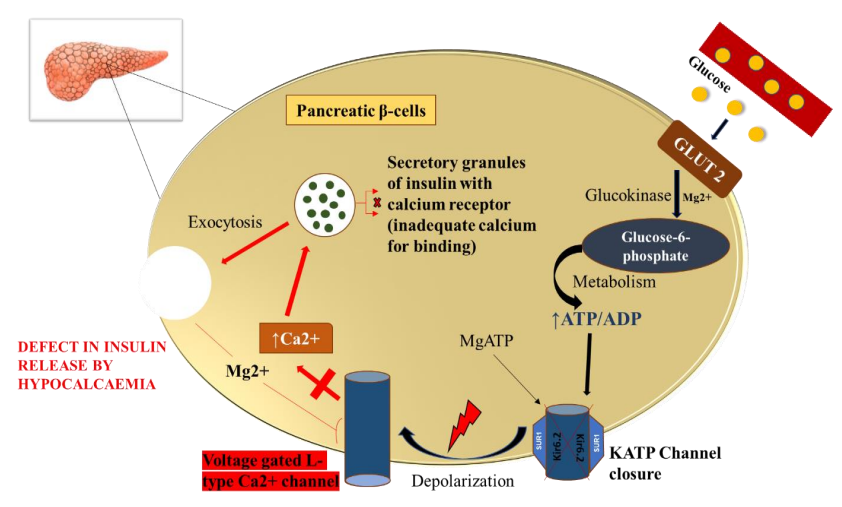

Fig 9. Defective insulin secretion by hypocalcemia (modified from Kostov, 2019)

Calcium is one of the central cations that take part in the activity of insulin secret, therefore, low. Therefore, low serum calcium may alter the insulin secretion mechanism, and it is significantly correlated with the abnormality of glucose level, insulin resistance, and $\beta$-cell function. Our study shows the significant correlation of low calcium levels in diabetic individuals; most of the diabetic individuals in this study have low serum calcium, which primarily includes females $(79.1 \%)$.

The prior studies show the comparison of diabetic with magnesium or diabetic with Calcium, but there is no comparison of diabetic with magnesium and Calcium together. In this study, we examined the correlation of both magnesium and Calcium in type 2 diabetic individuals. Compared to magnesium, low Calcium mainly occurs in diabetic individuals; thus, Calcium also plays a vital role in insulin secretion.

The electrolyte imbalance is significantly present in individuals with uncontrolled diabetes; 
therefore, serum electrolytes should be routinely quantified in those individuals [26]. From the data generated and the outcomes, diabetic individuals are prone to electrolyte imbalance [27]. This analysis shows a significant change in electrolytes (sodium and potassium) in diabetic, hypomagnesemia diabetic, and hypocalcemia diabetic individuals. Maintaining fluid balance is also essential in hypomagnesemia and hypocalcemia diabetic individuals.

\section{Conclusion}

In the present study, serum Calcium (Ca) and Magnesium (Mg) levels are imperative or essential in diabetic patients as they play a significant role in the insulin signaling mechanism for synthesis, secretion, and maintenance of blood glucose in diabetic individuals. Therefore, along with the hypoglycaemic agents, the supplementation of magnesium/ calcium could be suggested via dietary or drug supplements to those individuals. Since $\mathrm{Mg}$ and $\mathrm{Ca}$ plays a vital role in insulin synthesis, secretion, repair, and alteration. In addition to this, regular monitoring of electrolytes is essential to maintain fluid balance, which is essential for the diabetic individual.

\section{Conflict of interest : Nil}

Source of funding : Nil

\section{REFERENCES}

1. McPhee SJ, Papadakis MA. Diabetes mellitus and hyperglycemia. In: Masharani U, editor. Current medical diagnosis and treatment. 49th ed. USA: Churchill Livingstone The McGraw-Hill Companies, 2010;1079-1133

2. Diabetes blue circle symbol. International diabetes federation. Archived from the original. 2006.

3. Alberti KG, Zimmet PZ. Definition, diagnosis, and classification of diabetes mellitus and its complications. Part 1: diagnosis and classification of diabetes mellitus provisional report of a WHO consultation. Diabet Med. 1998;15(7):539-53

4. Roden, M, Petersen K, Shulman G. Insulin Resistance in Type 2 Diabetes. In Textbook of Diabetes, 5th ed.; Holt RI, Cockram C, Flyvbjerg A, Goldstein BJ, Eds.; John Wiley \& Sons: New York City, NY, USA, 2017; 174186

5. Xu H, Li X, Adams H, Kubena K, Guo S. Etiology of Metabolic Syndrome and Dietary Intervention. Int J Mol Sci. 2018;20(1):1

6. Muhammed KS, Bikha Ram Devrajani, Aftab Ahmed Soomro, Syed Zulfiquar Ali Shah, Tarachand Devrajani and Thanver Das, Hypomagnesemia in Patients with Diabetes mellitus, Department of Medicine, Liaquat University of Medical and Health Sciences
Jamshoro, Hyderabad (LUMHS), Pakistan, World Applied Sciences Journal. 2011;2 (10):1803-06

7. Liamis G, Liberopoulos E, Barkas F, Elisaf M. Diabetes mellitus and electrolyte disorders. World J Clin Cases. 2014;2(10):488-96

8. Guyton A, Hall J. Textbook of Medical Physiology; Elsevier Saunders: Philadelphia, PA, USA. 2006;348-81

9. Wang JL, Shaw NS, Yeh HY, Kao MD. Magnesium status and association with diabetes in the Taiwanese elderly. Asia Pac J Clin Nutr. 2005;14(3):263-9

10. Bertinato J, Wu Xiao C, Ratnayake WM, Fernandez L, Lavergne C, Wood C, Swist E. Lower serum magnesium concentration is associated with diabetes, insulin resistance, and obesity in South Asian and white Canadian women but not men. Food Nutr Res. 2015;59:25974

11. De Baaij JH, Hoenderop JG, Bindels RJ. Magnesium in man, implications for health and disease. Physiol Rev. 2015;95(1):1-46

12. Pham PC, Pham PM, Pham PA, Pham SV, Pham HV, Miller JM, Yanagawa N, Pham PT. Lower serum magnesium levels are associated with more rapid decline of renal function in patients with diabetes mellitus type 2. Clin Nephrol. 2005;63(6):429-36

13. Nair A, Hocher B, Pfab T, Konrad M, van Zeeland F, Bindels R, et al. Two Genetic Variants of TRPM6 Increase Risk for Hypomagnesemia Associated with Diabetes Mellitus Type 2. Biophysic J 2011;100(3):87a

14. Cruz KJ, de Oliveira AR, Pinto DP, Morais JB, Lima Fda S, Colli C, Torres-Leal FL, Marreiro Ddo N. Influence of magnesium on insulin resistance in obese women. Biol Trace Elem Res. 2014;160(3):305-10

15. Guerrero-Romero F, Rodríguez-Morán M. Magnesium improves the beta-cell function to compensate variation of insulin sensitivity: double-blind, randomized clinical trial. Eur J Clin Invest. 2011;41(4):405-10

16. Williams PF, Caterson ID, Cooney GJ, Zilkens RR, Turtle JR. High affinity insulin binding and insulin receptor-effector coupling: modulation by $\mathrm{Ca} 2+$. Cell Calcium. 1990;11(8):547-56

17. Cooper MS, Gittoes NJ. Diagnosis and management of hypocalcaemia. BMJ. 2008;336(7656):1298-302

18. Clapham DE. Calcium signaling. Cell. 2007;131(6):1047-58

19. Henquin JC, Ravier MA, Nenquin M, Jonas JC, Gilon P. Hierarchy of the beta-cell signals controlling insulin secretion. Eur $\mathrm{J}$ Clin Invest. 2003;33(9):742-50 
20. Ahn C, An BS, Jeung EB. Streptozotocin induces endoplasmic reticulum stress and apoptosis via disruption of calcium homeostasis in mouse pancreas. Mol Cell Endocrinol. 2015;412:302-8

21. Ojuka EO. Role of Calcium and AMP kinase in the regulation of mitochondrial biogenesis and GLUT4 levels in muscle. Proc Nutr Soc. 2004;63(2):275-8

22. Kostov K. Effects of Magnesium Deficiency on Mechanisms of Insulin Resistance in Type 2 Diabetes: Focusing on the Processes of Insulin Secretion and Signaling. Int $\mathrm{J}$ Mol Sci. 2019;20(6): 1

23. Kao WH, Folsom AR, Nieto FJ, Mo JP, Watson RL, Brancati FL. Serum and dietary magnesium and the risk for type 2 diabetes mellitus: The Atherosclerosis Risk in Communities Study. Arch Intern Med. 1999;159(18):2151-9
24. Noor MM, Nazir Q, Khan TM, Gillani S, Abbasi MA, Rauf A, Qureshi ZU. Association Between Low Serum Magnesium Level and Type 2 Diabetes Mellitus in Abbottabad. J Ayub Med Coll Abbottabad. 2019;31(2):2269

25. Pham PC, Pham PM, Pham SV, Miller JM, Pham PT. Hypomagnesemia in patients with type 2 diabetes. Clin J Am Soc Nephrol. 2007;2(2):366-73

26. Khan RN, Saba F, Kausar SF, Siddiqui MH. Pattern of electrolyte imbalance in Type 2 diabetes patients: Experience from a tertiary care hospital. Pak J Med Sci. 2019;35(3):797801

27. Naresh Kumar Jha. Study of lipid profile \& electrolyte levels in diabetes, Department of Biochemistry, Shree Narayan Medical Institute \& Hospital, Saharsa, Bihar, India, International Journal of Medical and Health Research.2017;3:146-8 